\title{
The Intraday Pattern of Trading Activity, Return Volatility and Liquidity: Evidence from the Emerging Tunisian Stock Exchange
}

\author{
Kais Tissaoui \\ Faculty of Law Sciences, Economic Sciences and Management of Jendouba, BP 8153 \\ Elmelga Jendouba, Tunisia \\ The International Finance Group, Tunisia, Manar University \\ Tel: 216-25-700-645Ｅ-mail: kaistissaoui@yahoo.fr
}

Received: Febriary 10, 2012

Accepted: March 14, 2012

Published: May 1, 2012

doi:10.5539/ijef.v4n5p156

URL: http://dx.doi.org/10.5539/ijef.v4n5p156

\begin{abstract}
The purpose of this paper is to investigate the intraday pattern of trading activity, liquidity and return volatility in the emerging Tunisian Stock Market (TSE) which is an order-driven market using intraday data covering the period October 2008 to June 2009. To achieve this objective, we have applied two methods: the temporal analysis that consists to estimate a dichotomy model for each variable by following the methodological approach of Vo (2007) and the second method is to apply the spectrum analysis by using the Fourier Transform fast (FFT). The results have shown that all identified variables are characterized by notable seasonality justified the rejection of the hypothesis of constancy $\left(\mathrm{H}_{0}\right)$. Both methods have shown the existence a seasonal pattern in U. The reason considered to justify this intraday behavior is the crucial role played by the problem of adverse selection especially between the two dimensions of liquidity: the spread and depth at the best limit. It should also be noted the effect of inventory management on the optimal allocation of the portfolio.
\end{abstract}

Keywords: Intraday pattern, Trading volume, Liquidity, Return volatility, Intraday data, FFT algorithm, Tunisian stock market.

JEL classifications: G12, G14, G15

\section{Introduction}

Intraday pattern in stock markets has attracted much research attention. This importance is due to the existence of intraday regularities in stock market that contests the Efficient Markets Hypothesis. To analyze this anomaly, we are forced to focus on the causes generating this behavior. The understanding of these causes has a significant interest in the microstructure theory in order to study the market reaction and the trading activity. Indeed, the obtaining of an efficient market is difficult in this situation since the arrival of new information generates abnormal micro-structural pattern called the "Intraday pattern". In this context, the researchers have tried to explain the sources of this anomaly by concentrating on the effect of information on strategies for insider trading and uninformed trading during the day.This anomaly may affect the market equilibrium. However, each investor wants to maximize his utility. This objective is legitimate but the question is how to achieve that? We are facing an enigma difficult to solve because the informed investors involved in the market take advantage of their private information when the uninformed intervene cautiously for the liquidity needs. Indeed, the strategic behavior of each investor depends on his position in the market. The literature of microstructure has focused on both types of information to explain behavior of intraday stock market. Public information comes on the market in the form "news". Degennaro and Shrieves (1997) have examined the importance of news in explaining the trading strategies of the investors and especially the market volatility. They divided the news into three categories based on Reuters: the macroeconomic news, the economic policies news and the news on interest rates. Cheung and Kwan (1992) presented an exhaustive literature review that focuses on the public information flow on the stock market. Kalev et al (2004) have used specific categories of news to companies listed on ASX as the announcement of results, dividends, changes in shareholding, the capital increase, the change of CEO, reports of accountants. According to Edmonds and Kutan (2002), most studies have examined the importance of public information by claiming that such information was not significant in explaining the variation of stock returns. This insufficiency in the role of public information obliged the researchers of the microstructure theory to examine the impact of public information by using the trading volume as a latent variable. Lamoureux and Lastrapes (1990) justified this theoretical approach by the fact that when public information is 
disseminated on the stock market, this information is unobservable by investors but motivate them to make transactions purchase or sale, and especially to achieve an optimal allocation of resources in spite of its randomness. Moreover, it is unevenly distributed and interpreted differently. Researchers have identified the role played by the transactions numbers, turnover and news as explicit variables representing the implicit public information. The use of such variables was justified also by Clark (1973), Tauchen and Pitts (1983), Anderson (1996). This focus coincides with two theoretical explanations based mainly on information: the MDH (The mixture of distribution hypothesis) and SIAH (the sequential information arrival hypothesis).

However, we must not focus only on public information but also on private information. This concept has represented, according to several analysts, the source of the problem of adverse selection in the stock market. Madhavan et al (1997) reported that the information flow and transactions frictions represented the factors explaining the intraday volatility and liquidity. While Admati and Pfleider (1988) and Foster and Viswanathan (1990) attributed the difference in transaction activity, liquidity and volatility to the ability of investors to benefit from their private information. Indeed, take advantage of this information is beneficial for informed investors "the insiders" while the possession of private information is considered by the uninformed investors 'liquidity traders' as information risk. According to the theory of asymmetric information, informed investors have private information on the value of quoted companies. This information would put them in a favorable position than other investors. Brockman and Chung (2001) have argued that the presence of insiders can reduce market liquidity since these informed investors profit from the private information by including it implicitly in stock prices through their trading activities. This requires the informed investors to respond to this informational disadvantage by reducing trading activity. But, the problem is aggravated when the uninformed investors accept this situation and remaining on the market as followers. Indeed, Admati and Pfleider (1988.1989) have proposed, through their theoretical model, a solution that uninformed investors must do their transactions together to minimize monopolistic position of insiders. The strategy of uninformed investors consists to limit their losses by a large proportion with insiders. In addition, if a great part of transaction is realized in the interior of trading day and not at the start or the end of day, the needs liquidity may reduce the insider-information risk. But the adoption of this strategy does not hide many threats which can meet the uninformed because the risk of loss of wealth is very important particularly in the presence of opportunistic insiders who take advantage of their private information.

In this study, we use two methods to achieve our objective: the temporal analysis that consists to estimate a dichotomy model for each variable by following the Vo (2007) methodology and the second method is to apply the spectrum analysis by using the Fourier Transform Fast (FFT). Our objective is to examine the intraday behavior of trading activity, return volatility and market liquidity on the Tunisian stock market in order to see if it has similar intraday patterns observed in other markets. Our empirical investigation is founded on a sample covering, in intraday frequency, 38 stocks continuously quoted on the TSE for the period (October 2008-June 2009). Many questions have been asked leading to reasonable solutions allowing the comprehension of that irregularity: Why does that anomaly exist? What are the causes generating the intraday pattern? Does the shape of the pattern differ from one market to another? Does the existing pattern depend essentially on the periodicities of the information flow? The main finding observed is that both methods have shown the existence of seasonal pattern in $U$ in Tunisian stock maeket. The reason defined to justify this intraday behavior is the crucial role played by the problem of adverse selection especially between the two dimensions of liquidity: the spread and depth at the best limit. It should also be noted the effect of inventory management on the optimal allocation of the portfolio. This present study also contributes to the related literature in several ways. To the best of our knowledge, our research is the first study that investigated the anomaly of seasonality on the Tunisian stock market after the promulgation of financial security information law since 2005 by the Financial Market Council. Second, we have used another dimension measuring liquidity. It is "the depth at the best limit". This variable is not used in any study on the Tunisian stock market to investigate the anomaly of seasonality. The unexploited of depth does not give a clear idea on the behavior of intraday liquidity.Third, the Fourier Transform fast (FFT) algorithm have never been employed in order to examine the seasonality in the Tunisian context. At last, we noted that a small number of empirical studies have focused on emerging stock markets particularly in countries of Middle East and North Africa(MENA). Major previous studies concentrated on developed stock markets.

The structure of the paper is as follows. Section 2 reviews the literature on the relationship between information and intraday pattern. Section 3 provides the theoretical explanation of intraday seasonnality. Section 4 describes the Tunisia stock market, data used and presents the definition of variables of trading activity, return volatility and liquidity. The section 5 presents the methodology used in the paper and the main findings. The paper concludes by summarizing the main conclusions 


\section{The Relationship between Information and Intraday Pattern in Literature}

The answer to these questions requires firstly the understanding of the relation between the information flow and this microstructural anomaly. "Intraday pattern" is certainly an anomaly due to its particular micro-structural features. The presence of this issue has motivated the researchs on the sources of this anomaly. However the detailed explanation of this notion obliges us to place it in an enormous quantity of literature. But the majority of the literature derived from developed countries, particularly the United States and Canada. Since the 80s, there have been a review articles on microstructure that have tried to analyze the existing patterns in the stock market. Admati and Pfleider (1988) have developed the theoretical foundations of trading pattern on the financial market. The authors have taken advantage enormously from the intraday transaction data since the daily data do not permit to investigate the behavior of the intraday market. They have demonstrated that the profile $U$ characterized the pattern of trading volume and return volatility. That means that trading volume and return volatility are higher at the beginning of trading day and in the end but they are weak during the day. Their results have confirmed the findings of Jain and Joh (1986). Wood, Mc Inish and Ord (1985) have tested empirically the existence of a U-pattern using transactions data minute by minute. They argued that the return and return volatility are distinguished at the beginning and the end of the trading day by a U-shaped profile. On the basis of this result, theoretical approach of Admati and Pfleider (1988) consists in understanding the reasons why transactions tend to be concentrated more on specific periods of the day than during other periods, and especially to know why the patterns of volatility and trading volumes are identical.Microstructure literature was interested enormously in studying the behavior of different intraday micro-structural variables but the first academic researches have been commenced in a market driven price. This market is very specific since it is characterized by the presence of market makers. According to Madavan (1992), this market represents a location where the investors may get the price quotations of market makers prior to submission their purchase orders and sales orders.

In this case, the market maker acts as an intermediary between buyers and sellers with prices determined before quantities. He is regarded as a liquidity supplier in the financial marketplace. Given these specificities related to the mechanisms used to accomplish the transactions and particularly recent availability of transactional data, quotations and orders issued in numerous markets around the world, Researchers on phenomena intraday stock market have exploited efficiently these conditions in order to confirm that U-pattern was the form most particular in the majority of markets in United states and other developed countries whether for return and volatility, liquidity and trading volume. But the results do not overlook another area that the pattern can take the form L-pattern, Y-pattern, or the opposite case of both forms as they depend largely of the characteristics of structural conditions in markets, mechanisms of transactions and the information flow.

For the markets of United States, the study of Wood, Mc Inich and Ord (1985) is considered the first study which was concentrated on the availability for this anomaly as the presence of seasonality in the stock market can contradict the market efficiency. They have shown that trading volume, return, return volatility and liquidity followed a U-pattern. All of these variables are high at the opening of the trading day but they become low during the trading day in order to increase at closing. More precisely the behavior of the market at the opening and the closing is different than within trading day in the NYSE. Indeed, their article examined empirically the nature of the generating process respecting the features of the transaction size, transaction frequency and transaction interval for the majority of actions in the NYSE. This research was enhanced by the analysis Pfleider and Admati (1988). These authors have verified the same intraday pattern for the Exxon Company stock during the year 1981. They have based their study on a theoretical model respecting two complementary characteristics: the process of information and the number of uninformed investors. The patterns shown in trading volume and return are mainly due to the strategic interaction between insiders and investors need to liquidity. The microstructure analysis has verified the presence of other forms of seasonality other than U-pattern still in the American context. Amihud and Mendelson (1987) have tried to test the effect of information on the behavior of returns at various times of the transaction day for 30 stocks forming the Dow-Jones. They proved that the returns at the opening are more variable than those at the closing market. The same result was confirmed by Stoll and Whaley (1990) for the NYSE stocks. They have also shown a high return volatility at the opening of the NYSE. Within the same context, Cerety and Mulherin (1994) have examined the existence of transitional character of volatility during the transaction day. They looked that the returns are more volatile at the opening than at the closing day. For their part, Mc Inich and Wood (1992) have studied the behavior of Bid ask spread within the transaction day depending upon 4 very important factors: the trading activity, risk, information and competition. They found that the behavior of liquidity measure shaped profile follows the reversed J-pattern. Other researchers are also interested to test the presence of this micro-structural anomaly in the U.S. stock markets such as Harris (1986), Mc Inish and Wood (1990), Foster and Viswanathan (1993), Ho and Cheung (1991). All these authors have supported the presence of a seasonal U-pattern of return 
volatility within the day. While other researchers have verified that the Bid-ask spread (Hashbrouck (1991a, b), and Mc Inich Wood (1992), Foster and Viswanathan (1993), Handa (1992), trading volume (Jain and Joh (1988), Mc Inich and Wood (1989.1990 b)), the number of transaction (Mc Inich and Wood (1989), Chan et al (1995)) follow a U-pattern for the stocks of NYSE. Similarly, Chan, Christe and Schultz (1995) have shown that the bid-ask spread of the stocks comprising the NASDAQ index follows a J-pattern. In other words, it becomes weak during the trading day but it increases again during the closing minutes. This finding confirmed by Chung and Van Ness (2001), the NASDAQ, before and after the reforms in 1997 that have affected the market. Chan et al (1993) have proved that the intraday bid-ask spread is higher immediately after the opening of market to decline enormously over the day and returns to his initial situation at the end of transactions. That same behavior has characterized the trading volume and return volatility.

Other interested authors are still looking for this anomaly in other developed equity markets. Such studies have benefited recently from the availability of the high-frequency data on these price-driven markets. In this context, Abhyanker et al (1997) contributed to enriching the existing literature by their study on the London Stock Exchange. They showed that the bid-ask spread, trading volume and return volatility are characterized by a seasonal pattern in the form $\mathrm{U}$, but this behavior differs depending on the liquidity of the stocks. However, the main lesson retained from the study of the intraday pattern in the price driven market was clear because no many countries adopt that transactional structure within their markets.

The majority of countries around the world introduced another system for trading within their stock markets. This system is characterized by a negligence of the role played by market maker in favor of the investor. In this sense, Madavan (1992) defined an order-driven market like a system in which investors place their orders in order to be executed by the method of the auction. The flexibility of this organization is mainly due the functioning because it can operate under continuous trading and gives investors the opportunity to submit their purchasing or selling orders for immediate execution against orders on the existing order book with prices determined multilaterally. While a quotation in auction provides an opportunity for investors to submit their orders before the opening in the marketplace to run when the market is opened with a price determined unilaterally. In order to understand the role played by the order-driven market, we had to try to distinguish this market with the price-driven market. Indeed, the order-driven market became more and more used as a suitable field to understand the anomalies. According to Ahn, Bae and Chan (2001), all the liquidity is supplied by the purchase orders and sales rders and not by the market maker. Without forgeting the role played by those orders as a source of volatility and transaction activity, researchers have exploited the situation enormously in order to show the seasonal pattern of each variable in this order-driven market.

In this framework, it is important to examine the informational content the order book by concentrating on the structural properties of the stock market. According to Noes and Skjeltorp (2006), this book represents the heart of the order-driven market through its ability to provide useful information on the liquidity and trading activity. On the developed stock markets as the Paris Bourse, Biais et al (1995) have confirmed the dependence of the pattern with the information effect. For their part, Hamao and Hasbrouck (1995) have concentrated on the stock market in Tokyo (TSE). This market represented one among the largest market in the world given its structural characteristics. This has allowed Lehman and Modest (1994) to investigate the behavior of the bid ask spread the trading volume, transaction and other variables of transactions by confirming the presence of a U-pattern. For his part, Vo (2007) attempted to show the pattern characterizing the liquidity, trading volume and volatility in the stock market (TSE) in the context specified by a dependency between the information flow and the investors. The results shown confirmed the presence of this anomaly in this market as the trading volume and the bid ask spread follow a U-pattern while the depth follows an inverted U-pattern. Recently, several researchers have oriented their microstructure studies on emerging stock markets adopting the order-driven system seen the improvement Technologies in information dissemination. This approach supports the view of Handa et al (1998, p.48) who said: "differently to a price driven market, the provision of liquidity in an order-driven market has received special attention in relation the microstructure literature."Within this framework it is part of the study of Brockman and Chung (1999) on the stock market in Hong Kong. They made two tests: an intertemporal analysis that allows them to confirm the inverted U-shaped profile of depth. And a cross-sectional analysis that enables them to demonstrate that the depth depends essentially on the adverse selection problem similar to the bid-ask spread. But the inter-temporal analysis appeared as a significant dependence of the behavior of liquidity with other variables such as price level, trading volume and volatility in order to verify that the provision of liquidity is a competitive dimension that will help to identify the best structure of mechanism transaction. Brockman and Chung (1998) also verified that the profile characterizing the Bid ask spread on the Hong Kong stock market is a profile in U. In a context of microstructure marked by a strategic interaction between insiders and uninformed, Lee, Fok and Liu (2001) have exploited the recent 
availability of order book data from the stock market in Taiwan. They have tried to analyze the pattern of intraday information and liquidity. The results indicated that investors using an investment strategy generating a J-shaped profile for the volume of transaction. Ahn and Cheung (1999) have studied the evolution of the intraday Bid ask spread and depth on the Hong kong stock market They have confirmed the existence of the U-shaped profile of the Bid ask spread and an inverted U-shaped profile of the Bid ask spread.Research in this context also has motivated Ahn, Bae and Chan (2001) to investigate the role played by the order book in order to explain this anomaly on the Hong kong stock market They have focused their study on the empirical relationship between transitional volatility and orders flow depending on the investment strategies of orders by insiders and uninformed investors. The results shown seem to provide a clear explanation of how the placements of orders since investors want to place them at the opening and closing session of trading. By adopting J-pattern according to the pattern of trading volume, the phenomenon of the presence of regularity will be privileged because it also goes beyond the anomalies on the market efficiency but it also allows considering the micro-structural side of the market. This anomaly has been a famous importance that has also very interested Choe and Shin (1993). These authors have tried to study the stock market in South Korea. They found that the indraday pattern of return of the KSP index (KOSPI) is a U-pattern either throughout the trading day or during the morning session. This anomaly is all the same examined in the context Filanda by Camerton-Forde et al (2007). These authors have analyzed the intraday liquidity and trading activity, volatility and information. They found that the transactions of insiders and uninformed are concentrated at the opening and closing of the session transaction which confirms the presence of a U-pattern. In addition, the seasonal anomaly is more and more examined by other researchers on other emerging markets like Kalev and Pham (2009) who have exploited the availability of order book data and transactions in Australian market (ASX) for a period from October 2001 to January 2002. They have verified that the presence of intraday regularities is clearly higher for the stocks of small or medium sized companies compared to the actions of large companies. They verify the exitence of an inverted U-shaped pattern of intraday trading activities and showed that informed traders search to minimize their transaction costs by the selection an optimum day of the week in order to trade. Indeed, they also show that informed traders determine the trading strategies depending on the time of day.

\section{3. "Intraday Pattern" in the Theory}

Several theoretical studies have attempted to explain this micro-structural phenomenon whether for a price-driven market or order-driven markets. They provided several theoretical explanations in order to conclude that this anomaly depends essentially on the information.In the financial market; the objective of all investors is to maximize their utility based on trading strategies depending on their possession of the information. This dependence represented the main process generating the micro-structural anomaly. But the availability of high frequency data which has motivated the research in this context. However, this new situation constituted empirically an appropriate ground so that the different patterns appear since the study of Wood et al (1985) on the NYSE. In order to achieve an explanation of what is "intraday pattern," the researchers focused their efforts to address this question theoretically: Why is there this anomaly is she? It seems more interesting to talk deeply as several explanations that have been used to support our thinking.

The first theoretical explanation of Admati and Pfleider (1988). They tried to answer three very important questions: Why were transactions concentrated in specific times of day compared to other times? Why are the returns more volatile in periods and less volatile in other periods? Why do the periods at high trading volume coincide with periods at high return volatility? In this context, they developed a theoretical model based on asymmetric information. This model essentially depends on the relationship between informed investors and investors need liquidity. They justified the presence of investor's liquidity in the market for strategic reasons in order to minimize the monopoly power of insiders since they seek to exploit their private information when uninformed investors make their transactions. Admati and Pfleider (1988) argued that the adoption of these behaviors on the part of insiders and investors need for liquidity can justify the behavior of intraday liquidity, trading volume, return volatility and return. Their theoretical model represented the first theoretical essay explaining the theory "Intraday pattern" in the financial market. Indeed, this theory has shown that all patterns are the result of strategic interaction between insiders and uninformed investors. In addition, their theoretical model is based primarily on investor liquidity needs and their actions in order to identify the different types of patterns. Investors seek the good times to make their transactions when market liquidity is high and transaction costs are down. This approach is also adopted by insiders who choose to do their transactions when the market is liquid. This strategic interaction between these two types of investors generates a situation of concentration of transactions at specific times during the trading session. This confirms the theoretical proposition that the trading of insiders at precise moments reflect the importance of private information. More precisely, the assertion that the increase in transaction costs depends on the occurrence of the problem of asymmetric information. This group of informed and uninformed investors at specific times of trading 
day contributes to the development of a theoretical explanation of different types of intraday pattern. These patterns depend mainly on high liquidity and low cost of information asymmetry.

Another theoretical explanation has been advanced by Brock and Kleiden (1992) on the reasons of the emergence of seasonality in trading day. They developed a model showing that the demand for transactions at the opening and closing of the market is high and less elastic than other times of trading day. They tried to answer a very important question: why are transactions bent on opening and closing of the market? They focused their analysis on the necessity to rebalance the portfolio of actions at the opening and closing of the trading session by investors.First, the accumulation of information is made the night after market closure, ie during periods of non-transaction, generating a deviation from the optimal position. This situation obliges investors to increase their transaction at the opening of the market order to arrive at the optimum position and reach equilibrium of their portfolio. Second, before moving to the non-transaction period, the optimal position at the end is different from the optimal position during the trading day, forcing investors to increase their transaction at the end to achieve an optimal position. Their model shows that the grouping of transactions at the opening and closing for the goal in order to rebalance the portfolio that can lead to U-shaped profile. Kleiden Brock (1992) showed that the occurrence of seasonality in session is caused by the monopoly power of market makers and especially their willingness to have an optimal position at the close of the trading day before receiving information during the transaction and also to the inelastic demand of investors. They developed a model showing that market makers have filled their monopoly and exploit the inelastic demand of investors for making transactions at the opening and closing by increasing the bid ask spread.The main result of Brock and Kleiden (1992) was that seasonality depends mainly on the investor needs to rebalance their optimal positions. However, it should be noted that these authors have inspired their explanation the following lessons: First, the trading volume follows a U-pattern throughout the trading day.Second, the trading volume and liquidity are positively correlated due to the relentless demand for liquidity at the opening and closing of the market. In addition, the bid ask spread follows a U-pattern similarly to the trading volume. Third, the volatility is not correlated with trading volume and liquidity because the information flow is constant and does not follow "intraday pattern». Indeed, with the arrival of new information during the period of non-transaction, the portfolio that is optimal during the closure of the preceding trading day will be suboptimal when the new session will begin. Therefore trading activity increases immediately after the opening since investors can attempt to rebalance their portfolios.

\section{Description of the Market, the Dataset, Definition of Variables}

\subsection{Presentation of BVMT}

The Tunisian Stock Exchange is a private organization whose the shareholders are the stock market intermediaries. It is the enterprise that manages the stock market. Its operation is subject to control by the council of Financial Markets (CMF). The BVMT is a centralized market and governed by the orders because the investment can be achieved only through the brokers. Trading of shares takes place through quotation system developed by the Euronext group. Purchase orders and sales orders introduced in this system will be confronted depending on the degree of liquidity in two ways: The less liquid stocks are quoted according to the auction mode. The most liquid stocks are quoted according to the continuous mode. The BVMT is organized by the Law No. 94-117 of November $14^{\text {th }}, 1994$ on the reorganization of the financial market. But this legislation is inadequate for the development of BVMT, which motivated BVMT authorities to modify the Law No. 99-92 of August $17^{\text {th }}, 1999$ on the recovery of financial market. In the same context, there is the law No. 2005-96 of October $18^{\text {th }}, 2005$ on the strengthening of Financial Security. This law is an extension of the legislative reforms introduced by the financial authorities to strengthen financial transparency in the Tunisian stock market. Besides the legal reforms, there are other reforms in the Tunisian Stock Exchange. These include the introduction of an electronic trading system called SUPER-CAC UNIX in October $25^{\text {th }}$, 1996. This system is managed by a central computer which makes the comparison of purchase orders and sales orders. On December $3^{\text {rd }}$, 2007, the Tunisian Stock Exchange launched the new version of the electronic trading system V900 developed by Atos Euronext. All these reforms have focused on the development of the Tunisian Stock Exchange to enhance the stock market, to increase the trading activity and to restore the investor confidence that will be reflected by the liquidity evolution. The trading day in the Tunisian stock market pre-opens from 9 am to $10 \mathrm{am}$. During this period, the purchase orders and sales orders are entered without giving effect to the transactions. As soon as the market is open, the system determines an opening price that will be used only to transactions by the opening auction at $10 \mathrm{am}$. After opening and during the continuous session that lasts from $10 \mathrm{am}$ to $2 \mathrm{pm}$, the introduction of an order in the system can generate an instantaneous transaction when there is an opposite order.

\subsection{Data}

In this study, we analyze the intraday behavior of trading activity, volatility and liquidity of stocks in the Tunisian stock market. Our sample includes 38 shares that have a continuous trading for a period of 9 months spanning the beginning of October 2008 to the end of June 2009. It consists of a database composed of two intraday files: a 
trading file and quotation file. The transaction file contains intraday transaction prices and quantities next to the code of each stock on the transaction system, the date and transaction time. The second file represents the set of limit orders purchases and sales next to the code of each purchase order and sale order, the date and time entry of the order, the ASK price, the BID price entered by the intermediary stock exchange and the quantity appropriate for each ASK price and BID price. However, it should be noted that the constraints have made our task difficult in order to constitute our final database: at this level, we must mention the narrowness of the Tunisian secondary market and especially the problem of illiquidity of certain listed securities. The choice of this period in our study is justified by the recovery of Tunindex index in the first half of 2009, of its performance compared to the final quarter of 2008. It was able to achieve its level of September 2008 at the end of April 2009. To attain the final list of our study, we conducted several stages of filtering Initially, the list contains 50 stocks However, we exclude 12 shares listed on fixing since at this level, the law of supply and demand is not involved in this quotation type. Table 1 contains the final list of securities in our study. It provides the code and identification name of the 38 shares quoted continuously in the Tunisian stock market as well as the sectors they belong to. In addition, we determined the descriptive statistics of our sample. The details of this descriptive analysis are presented in Table 2.To conduct our research, this table shows that the daily average of trading volume per session during our retained period is about 34 transactions. The average number of transactions traded per day is 17,506. In addition, it is clear that the number of sale orders exceeds the number of purchase orders. The total amount of transactions performed during the period of study was 121399 567. The total maximum quantity negotiated is 20163175 (Attijari Bank) while the total minimum quantity negotiated is 119,409 (BTE-ADP).

\subsection{The Determination of Variables}

4.3.1 The return: Generally, we begin our analysis by the calculation of Stock return. From the transaction file, we are applying the following formula on the series of transaction prices of 38 securities traded continuously in order to measure geometrically the rate of return. The geometric rate of return is used in our study because several previous studies have adopted it.This authorizes us to compare our results with those from other studies.

$$
\mathrm{R}_{\mathrm{t}}=\left[100 *\left(\operatorname{Ln}\left(\mathrm{P}_{\mathrm{t}}\right)-\operatorname{Ln}\left(\mathrm{P}_{\mathrm{t}-1}\right)\right)\right]
$$

with: $R_{t}$ : Represents the return on stock i in interval t, $P_{t}$ : Represents the closing price of stock i in interval t. $P_{t-1}$ : Represents the closing price of stock $\mathrm{i}$ in interval $\mathrm{t}-1$

4.3.2 The trading volume: Likewise to the return, the trading volume indicates the number of shares traded on each interval. We can measure it by this formula. The reason for using the natural logarithm is to normalize this variable so as not to fall into fallacious estimates.

$$
\mathrm{V}_{\mathrm{t}}=\left[100 * \operatorname{Ln}\left(\mathrm{NAE}_{\mathrm{t}}\right)\right]
$$

With: $V_{t}$ : Represents the trading volume of stock $i$ in interval t. $\mathrm{NAE}_{t}$ : NAB: Represents the number of shares traded for stock $i$ in interval $t$.

4.3.3 The return volatility: To proxy return volatility, the squared values of intraday stock returns are used. Brailsford (1996) employed the squared as volatility proxies for the Australian stock market.

$$
\mathrm{R}^{2}=\left[\mathrm{R}_{\mathrm{t}} * \mathrm{R}_{\mathrm{t}}\right]
$$

4.3.4 The quoted spread: The difference between the best of limited price for sale and the best of limited price of purchase represents the quoted spread.

$$
\mathrm{QSPR}_{\mathrm{t}}=\left[\left(\mathrm{P}_{\mathrm{B}}\right)-\left(\mathrm{P}_{\mathrm{A}}\right)\right]
$$

with:

$\mathrm{QSPR}_{\mathrm{t}}$ : The quoted spread in the interval t. $\mathrm{P}_{\mathrm{B}}$ : The best limit price to buy (BID) of the interval t. $\mathrm{P}_{\mathrm{A}}$ : The best limit price to sell (ASK) of the interval t.

4.3.5 The Depth: The depth indicates the quantity available for the purchase and sale, for each price level at a given instant.

$$
\operatorname{DEP}_{\mathrm{t}}=\frac{\left(\mathrm{Q}_{\mathrm{B}}+\mathrm{Q}_{\mathrm{A}}\right)}{2}
$$

With : $D_{E P_{t}}$ : Depth in the interval t. $Q_{B}$ : The quantity available at the purchase price in the interval t. $Q_{A}:$ The quantity available at the selling price in the interval t. Once all the series of all variables are determined, we need to construct a cross-sectional database. To do this, Abhyanker et al (1997) have presented an empirical methodology to achieve this aim. For each time interval $t(t=1 \ldots 24)$. We compute the weighted average for all shares $i(i=1 \ldots 38)$ 
through all the trading sessions $\mathrm{j}(\mathrm{j}=1 \ldots 184)$. The study of the seasonal anomaly in the Tunisian stock market will be investigated as soon as the cross-sectional database is created.

\section{Methodology and Empirical Results}

Our study is inspired of the Vo (2007) study on the Toronto stock market. At this level, the availability of high-frequency data on the Tunisian stock market especially after the implementation of the Financial Security Law in 2005 motivated us to use this data to analyze profoundly the seasonal liquidity, volatility and trading activity and especially to study the different correlations between the micro structural aggregates. However, before we implement our methodology, we, first, try to identify the variables necessary to respond to our research questions. The achievement of the importance of intraday analysis of the seasonal anomaly requires the division of trading day in equal intervals of time. The application of this empirical approach of our sample allows us to divide the trading day from 10 am to 2 pm over 24 intervals and retain a sampling interval of 10 minutes each. Indeed, the analysis of seasonality requires, first of all, the determination and definition of variables in our study.

\subsection{Testable Hypothesis}

In this section, we investigate the intraday behavior of trading activity, volatility and liquidity. To do this, we analyze graphically all variables in order to finalize with the estimation of models. Table 3 refers to the standardized average values for all variables of 38 securities for each time interval during the trading day. To accomplish our detailed analysis of the regularities in the Tunisian stock market, we needed to formulate the following hypotheses. The market efficiency hypothesis considers that the stock prices include all the information available on the market. Indeed, this hypothesis supports the idea that the variables of liquidity and transactions are constant throughout the trading day. So our approach is based on the following hypothesis:

Hypothesis 1 : The evolution of variables of trading activity, return volatility and liquidity are constant during the trading day.

Hypothesis 2: The evolution of variables of trading activity, return volatility and liquidity are not constant during the trading day. At this level, we will attempt to test these hypotheses on the Tunisian stock market in order to analyze the evolution of different variables. It would certainly be interesting to follow an empirical process based upon two paths.

\subsection{The Graphical Analysis of Intraday Behavior of the Trading Activity, Return Volatility and Liquidity}

It is therefore appropriate to start with a graphical analysis that is important for viewing the behavior of different variables in the Tunisian stock market. Table 3 presents the cross-sectional average of standardized return, standardized trading volume, Standardized return volatility, standardized quoted spread and standardized depth for each interval of 10 minutes of the trading day. The following figures show the evolution of liquidity and trading activity over time in the Tunisian stock market.

From the visualization of different figures, we can observe that the figure 1 displays the intraday movements of return during the trading day. It reveals that the intraday behavior of return follows almost the U-Pattern. During the first minutes of trading, the return attained a high level that is equal to 2,049. This return decreases and varies between -1 and 1 throughout the trading day. At the end of quotation, it achieved a peak that reaches 3,451 . Hence, the confirmation of our second hypothesis. Certainly, we can say that this result coincides with the results shown on the order-driven market (Bildik (2001)).Second, the trading volume is globally variable in the day. Figure 2 also highlights that the configuration of intraday trading volume is in $\mathrm{U}$ and more precisely in $\mathrm{W}$. We notice, however, a high trading volume over the first ten minutes of the session quotation as well as a strong increase at the close of the day. However we find in the middle of the day that the trading volume comes to decrease after the first interval in order to increase again until reaching the value 1 at 11:30 am. This persistence of the growth of the trading volume has been interrupted and has declined again. Third, figure 3 shows clearly that the intraday behavior of return volatility follows the shape $\mathrm{U}$. We observe that high return volatility exists at the beginning of the session quotation. However this volatility has declined rapidly and continues to decrease throughout the day in order to pick up again in the last ten minutes. The latter result is consistent with the results of Ahn, Bae and Chan (2001).In addition, the figure 4 shows that the quoted spread also follows the U-shaped profile. We notice that the spread is high at the beginning of the market followed by a reduction during the two following intervals. During the trading day, the liquidity has decreased again except a slight reduction at the level of interval 15 to regain on the rise to the market close. This finding of U-shaped profile coincides with the results of Chung et al (1999) on the NYSE and those of Vo (2007) on the TSE. Finally, the visualization of the figure 5 provides information on the intraday behavior of depth. This figure also supports the U-shaped profile. But this profile is different compared to the profile of the quoted spread. The depth was high at the beginning of the session, and then decreases throughout the trading day 
and it is growing during the last half hour before the closure of negotiations. This showed U-shape in the Tunisian stock market is consistent with the proven results on the NYSE by Lee, Mucklow, and Ready (1993) and on the Paris stock exchange by Biais et al (1995) and the SEH justified by Ahn et al (2001).

However, the question asked here is to know whether our proposed hypotheses in accordance with the theory of efficiency have been confirmed or not. In the first stage, the evolutions profiles show that the Tunisian stock market is liquid at the beginning of quotation, since we find that the spread and the depth at the best limit are very high during the first 10 minutes in order to decrease during the next 20 minutes. While during the trading day, the Tunisian stock market is illiquid since the price dimension of liquidity (quoted spread) increased while the quantity dimension (the depth at the best limit) is down. But the observation of the profiles confirms the finding of a upward trend of market liquidity during the last 30 minutes of quotations. It is clear that the spread and depth at the best limit are very high at the end of quotations. This change in liquidity at the Tunisian stock market tends to confirm the presence of anomaly of seasonality.

In a next phase, we observe an intraday evolution very similar of trading activity with that of liquidity. A possible interpretation, consistent with the results obtained here would be that the hypothesis 2 presented above was accepted either for liquidity variables or trading activity variables. These results coincide with the results shown by several empirical studies such as studies of Jain and Joh (1988), Foster and Viswanathan (1993), Jang and Lee (1993) on the NYSE and Chan, Christie and Schultz (1995) on the NASDAQ. For this, the question that arises at this level, why do these patterns exist? It is necessary to submit briefly the explanations justifying the presence of this seasonality in liquidity and trading activity in the Tunisian stock market. We will build our analysis on two theoretical foundations: the adverse selection theory and inventory theory. Initially, the simultaneous analysis of the spread and depth will doubtlessly allow us to have a better comprehensive view on the supply of liquidity in the order book. However, the primary objective of investors is to position itself in an optimal way on the market and rebalance their portfolios by increasing the spread and decreasing the depth in order to cope with the risk of adverse selection.

However, our results showed that the spread and the depth have the same behavior at the opening and closing trading. In other words, there is an improving liquidity during the first minutes and last-minute of quotation. At the opening, the improving liquidity can be attributed to the intense competition between the agents of limit orders that place orders rapidly such that they are executed in order to search the profitable opportunities although the risk of detention of private information by informed investors is very important. Furthermore, this result does not agree with the hypothesis of asymmetric information that requires an illiquid market at the opening. Whereas at closing we observe an increase of two dimensions of liquidity. This change in the degree of liquidity at the closing might be explained by the need for investors to have an optimal inventory position, and especially to execute them by the price closing .But as from 10:30 a.m. we notice a deterioration in liquidity as investors become more conservative due to the increasing the risk of adverse selection. This prudence is reflected in a higher spread and low depth This transaction strategy adopted by the underwriters to limit orders appears very different to that adopted in other markets.

In a second step, we are proposing to analyze and explain the dynamics of intraday trading activity. The results have shown that the Tunisian stock market is characterized by a concentration of trading volume at the opening and closing of the trading session. While inside the trading day, trading volume has remarkably declined. This U-shaped profile, according to Lee, Fok and Liu (2001), represents a global phenomenon, since several studies have revealed the presence of such intraday behavior as the works of Wood, McInish and Ord (1985), McInish and Wood (1990a), McInish and Wood (1992) and Lockwood and Linn (1990) respectively on the NYSE and the TSE. And the works of Chow, Lee, Liu (1994) and Liu (1994), Ho and Cheung (1991), as well as Ho Cheung and Cheung (1993) respectively on Taiwan stock market and SEHK. Jain and Joh (1988) have justified the high level of trading activity precisely at the opening by the willingness of investors to exploit the collected information the eve and before the opening of the market in order to achieve their transactions. Admati and Pfleiderer (1988) suggest that uninformed investors react together to make transactions to limit the informational advantage of insiders. For their part, informed investors attempt to exploit their private information and make transactions at the opening before this information becomes public. Brock and Kleidon (1992) provide an important explanation for this anomaly. They show that investors exploit the advent of new information and make transactions at the opening and closing of the market for the objective of rebalancing their portfolios. Next to the profile of trading activity, the U-profiles of return and return volatility may be allocated to the increased important accumulation of information the eve and before the opening of the Tunisian stock market. These results imply that the collected information (public or private) will be immediately and implicitly incorporated into stock prices since the market opening. Our results coincided with the results of Wood et al (1985), Harris (1986), Jain and Joh (1988) on the NYSE, Copeland and Jones (2002) on the Korean market. But it must be mentioned that the attribution of high levels of return and return volatility at 
the opening and closing quotation in the Tunisian stock market, is only due to the information flow, is insufficient. Since the previous literature has shown the existence of a very important factor generating this anomaly. Amihud and Mendelson (1987), Stoll Whaley (1990) have highlighted the importance of trading in fixing on the return and volatility. They have shown that the return and the volatility calculated on the basis of price fixing are high during the first minutes and the last minutes of trading.

\subsection{The Empirical Analysis of the Regularities of Intraday Trading Activity, Volatility and Liquidity}

The graphical analysis has shown the presence of the anomaly of seasonality in the Tunisian stock market. It therefore seemed interesting to adopt and to estimate the same methodological approach of Vo (2007) to verify this result. To test the significance of different patterns of liquidity, volatility and trading activity, standardized variables are regressed on a set of dummy variables representing the intraday intervals. The following parameters of the model are estimated by using OLS.

$$
\begin{aligned}
& S D R_{t}=\alpha_{0}+\sum_{k=1}^{n} \alpha_{t} D_{k}+\varepsilon_{t} \\
& S D V_{t}=\alpha_{0}+\sum_{k=1}^{n} \alpha_{t} D_{k}+\varepsilon_{t} \\
& S D R_{t}^{2}=\alpha_{0}+\sum_{k=1}^{n} \alpha_{t} D_{k}+\varepsilon_{t} \\
& S D S P R E A D_{t}=\alpha_{0}+\sum_{k=1}^{n} \alpha_{t} D_{k}+\varepsilon_{t} \\
& \text { SDDept } h_{t}=\alpha_{0}+\sum_{k=1}^{n} \alpha_{t} D_{k}+\varepsilon_{t}
\end{aligned}
$$

Where, $\mathrm{SDR}_{\mathrm{t}} ; \mathrm{SDV}_{\mathrm{t}} ; \mathrm{SDR}_{\mathrm{t}}^{2} ; \mathrm{SDSPR}_{\mathrm{t}} ; \mathrm{SDDepth}_{\mathrm{t}}$ represent standardized variables of return, volatility, trading volume, spread and depth in the interval generating t. $\mathrm{n}$ is the number of intervals in the trading day with $\mathrm{n}$ ranging from 1 to 24 . $D_{t}$ are dummies variables equal to 1 if the observation $t$ occurs in the interval $k, 0$ else. In addition, our sample is over 30 . Above all, we estimate different equations for each stock market using the OLS estimation method. Thus, we exploit the t-statistics that is consistent against heteroscedasticity and autocorrelation in order to justify the significance of estimated parameters.

The estimation results are reported in Table 4. We are finding that the return is high at the beginning of the market since $\alpha_{1}$ is statistically significant and positive and very superior to the other successive coefficients. But this decreasing trend throughout the day did not last long in order to achieve its high level at the closing of market. This result is translated by an increase of coefficient values during the last thirty minutes $\left(\alpha_{24}>\alpha_{23}>\alpha_{22}\right)$. Statistical significance and the positivity of these coefficients absolutely confirm the result that the return reaches its higher level at the end of the trading day. It is no surprise from the above that our results maintain the results generated by graphical analysis. In addition, we use the unconditional correlation as a measure of the degree of liaison between all the variables in our study. The observation of the unconditional correlation matrix confirms the presence of a very high positive correlation between the return with other variables (the trading volume $(0,99$ and 0,98$)$, the return volatility $(0,95$ and 0,99$)$, the spread $(0,80$ and 0,99$)$ and the depth $(0,64$ and 0,97$))$ respectively during the first three intervals and the last day of trading. For the trading volume we notice that it reaches a high level at the beginning and closing of the market since the results have shown that coefficients $\alpha_{1}$ and $\alpha_{24}$ are statistically significant and positive and superior to other dummy coefficients estimated in the model (9). This also confirms the result shown by the graph of the trading volume profile. Similarly to the trading volume, we also observe that the return volatility is significantly high in the first and last minutes of the trading session. This is reflected by the significance and positive coefficients $\alpha_{1}$ and $\alpha_{24}$ and more specifically their superiority compared with other coefficients.

According to the above, we can mention that there is a positive relationship between trading volume and return volatility during the first minutes and the last minutes of trading day. This finding corresponds to the theoretical 
proposition of Admati and Pfleiderer (1988) that periods of high trading volume tend to be periods of high return volatility. According to Easley and O'Hara (1992), we can also explain this situation by the fact that a high trading volume represents an indication of the arrival of insiders on the market. This will increase the risk of transactions with investors and especially the probability of achieving losses and therefore the opportunity to observe high levels of the return volatility during these periods. The analysis is thus clearer regarding the interpretation of the correlation matrix. Indeed, the results have shown the unconditional positive correlation between trading volume and return volatility $(0,96$ and 0,99$)$ respectively for the first and last three intervals during the trading session.

For the dimensions of liquidity, the regression results have shown that the spread is characterized by a high level at the opening and closing of the market compared to the inside of the trading day. The values of estimated coefficients confirm our results of a U-shape since we have observed that the coefficient $\alpha_{1}$ is statistically insignificant and negative but higher than the coefficients $\alpha_{22}$ and $\alpha_{23}$ that are significant. Similarly, the coefficient $\alpha_{24}$ is significant and positive. It attained a high level compared to the coefficients $\alpha_{22}$ and $\alpha_{23}$. To understand this phenomenon, we can deduce the existence of a direct relationship between the return volatility and the spread for the opening and closing of the market. Foucault (1999) justified this nature of relationship with the demonstration that when the market is volatile, the probability to encounter insiders increases, which will increase the losses of the uninformed investors. To resolve this problem, they try to place limit orders to buy at low prices and limit orders to sell at high prices. This investment strategy generates a higher spread. For depth, we have found that the coefficient $\alpha_{1}$ is significant and positive. This means that this quantity dimension of liquidity is extremely high during the first minutes of trading. But this increasing trend does not long remain in order to decrease during the trading day $\left(\alpha_{1}>\alpha_{2}>\alpha_{3}>\alpha_{4}>\alpha_{5}>\alpha_{6}>\alpha_{7}>\alpha_{8}>\alpha_{9}>\alpha_{10}>\alpha_{15}>\alpha_{16}>\alpha_{17}>\alpha_{18}>\alpha_{19}>\alpha_{20}>\alpha_{21}\right)$. Yet during the last minutes of trading, we noticed that liquidity is characterized by a remarkable increase. This behavior is reflected by the significance and negativity and especially the superiority of $\alpha_{24}$ compared to $\alpha_{22}$ and $\alpha_{23}$. The most surprising from the above is that although the high level of volatility at the opening and closing of the market, liquidity seekers do not hesitate to increase their spread but in return they retain high levels of the depth at the best limit. Similarly to the trading volume, we also notice, from the unconditional correlation matrix, that there is a positive correlation of the return volatility with the spread (0.94 and 0.99$)$ and depth at the best limit $(0.83$ and 0.98$)$ respectively during the first three and last intervals of the transaction day. This result does not coincide with the explanation of Foucault (1999) that the strategic behavior of the Agents of limit orders for these active periods is the increase of the spread and reducing of the depth at the best limit in order to protect against the risks mentioned above. The justification that we can offer is that the need for liquidity and rebalanceing the optimal portfolio requires such applicant's liquidity to adopt this strategy. We apply reconciliation between intraday behavior of the depth and trading volume. Our results have shown the existence of high level of depth accompanied by a high level of trading volume. This result was confirmed by the presence of a very high positive correlation between trading volume and the two dimensions of liquidity (the spread (0.82 and 0.98) and depth at the best limit (0.66 and 0.99)) for the first and last half hour of the trading day. We think that this result is different from that shown by Lee et al. (1993), Ye (1995) and Kavajecz (1999). They have proven that during these trading periods, the trading volume is characterized by a high concentration when the depth reaches a low level. Indeed, this explanation implies more than the strategic actions of the applicants of liquidity represent the main source to have this type of relationship. In addition, the high level of spread and depth at the beginning and the end of the session shows that investors do not take into consideration the risk of non-execution of their orders whose objective is to have very advantageous position in the market in order face competition with other suppliers of liquidity. Therefore, the extension of two dimensions of liquidity is verified by the existence of positive unconditional correlation between spread and depth at the best limit.

\subsection{The Spectral Analysis of the Behavior of Intraday Trading Activity, Return Volatility and Liquidity}

After having applied the graphical and empirical analysis, the next step consists of applying the spectrum analysis. The Fourier series development is founded on the principle that every periodic function of time $x(t)$ can be decomposed into an infinite sum of sines and cosines of which frequencies start at zero and increase in integer multiples of a basic frequency $f_{0}=1 / T$, where $T$ is the period of $x(t)$. To account for time series, we decompose the process $\mathrm{x}(\mathrm{t})$ in periodic components by adopting the criteria of frequencies. In fact the Fourier transformation is one of the methods frequently used in spectral analysis. The Fourier transformation has already been considered as a particular mathematical case of Laplace transformation. This method can automatically detect the seasonality and more specifically to analyze the frequency of the process $\mathrm{x}(\mathrm{t})$. In other words, the Fourier transform can be used to diagnose the periodic structures in time series data. It transforms an original function which is often a periodic function into another, which is called the frequency domain representing the original function. According to the Fourier theorem, any time series can be formulated as the sum of sines and cosines of different frequencies and 
magnitudes. The Fourier transform allows decomposing a series $t \mathrm{X}(\mathrm{t}=1 \ldots \mathrm{n})$. We can write the Fourier development as follows:

$$
x(t)=\alpha_{0}+\sum_{k=1}^{\infty}\left(\alpha_{k} \cos \left(2 \pi k f_{0} t\right)+b_{k} \sin \left(2 \pi k f_{0} t\right)\right)
$$

By knowing the basic frequency and the function $\mathrm{x}(\mathrm{t})$, the achievement of a Fourier transform consists in determining all values $\alpha_{k}$ and $b_{k}$ that make up the series. The Fourier transform adopts another form that can be represented by the following function:

$$
\hat{f}(w)=\int_{-\infty}^{+\infty} f(t) e^{-i w t} d t
$$

The inverse Fourier transformation is as follows:

$$
f(t)=\int_{-\infty}^{+\infty} \hat{f}(w) e^{i w t} d w
$$

We had necessary to use Matlab in order to apply the spectrum analysis of the various series. However, the spectrum analysis has allowed us to appreciate the existence of seasonality and especially to take part in the determination of the appropriate pattern for all variables mentioned above. The application of Fourier transform (FFT) confirms our results proven above. To illustrate this point, we figure the results of the application of spectrum analysis on all variables by graphics with the abscissa and the ordinate respectively the frequency and the magnitude. These specters show clearly the existence of seasonality that is manifested by significant spectral peaks in seasonal frequencies at the opening and closing trading days reflecting a seasonal effect which characterizes all variables of liquidity, volatility and trading activity.

This type of frequential analysis is generally used to prove that a signal has the dominant frequencies: when we represent the spectra, we see that there were some significant peaks, indicating that the signal possesses a certain periodicity in the corresponding frequencies. Figure 6 illustrates the spectrum of the series standardized return. We find that there exists a significant peak at the opening trading day with a magnitude of 5.771 and a frequency of $0.001667 \mathrm{KHz}$ and another significant peak at the end of the day with magnitude of 5.771 but frequency of 0.05167 $\mathrm{kHz}$. Indeed, the series of return analyzed and presented two remarkable periodicities when frequencies present a remarkable peak. Similarly, the results illustrated in Figure 7 for the spectrum of standardized trading volume, showed that there were some large fluctuations at the start of trading session with a magnitude of 15,06 and a frequency of $0,001667 \mathrm{KHz}$ and also at the end of trading for a magnitude of 15,06 but the frequency of 0,5167 KHz. The analysis of the frequential evolution of standardized return volatility illustrated in figure 8 , indicates that the presented series is characterized by a considerable variability since there is a significant peak at the beginning of the trading session with a magnitude of 17,57 and a frequency of $0,001667 \mathrm{KHz}$ and another significant peak at the end of the day with a magnitude 17,57 and frequency of $0,5167 \mathrm{KHz}$.

Regarding the dimensions of liquidity, Figure 9 illustrates the spectrum of the standardized quoted spread. We also found that there is a great variability justified by significant peak at the opening of trading day with magnitude 18 , 86 and frequency of $0,001667 \mathrm{KHz}$ and another significant peak at the close of the day with magnitude but a frequencyof 0, $05167 \mathrm{KHz}$. For the other dimension of liquidity, it is clear from Figure 10, that the spectrum analysis of the depth confirms the existence of significant peak at the opening with a magnitude 31,24 and a frequency of $0,5167 \mathrm{KHz}$ and another significant peak at the close with a magnitude 31,24 and frequency of 0,5167 KHz.

Finally, our showed results in this study are important in both theoretical and applied implications. On the theoretical level, our study agreed with the theory of microstructure and more precisely with the theoretical explanation of the presence of an anomaly in the financial market by asymmetric information. On the applied level, our results can build an appropriate analysis to investors to be able to implement their strategies of speculation. More precisely, speculation is characterized by taking a risky position on a placement to invest on the future evolution of stock in order to accomplish capital gains. Indeed, investors, through their knowledge of the seasonal pattern characterizing trading activity, return volatility and liquidity, may react and achieve transactions for the adequate moments they want.

\section{Conclusion}

We have attempted in this paper to clarify the intraday behavior of liquidity, volatility and trading activity in financial markets. The existence of seasonality characterized this behavior which will contradict the hypothesis of market efficiency. The previous literature has shown the existence of this micro-structural anomaly since the study 
of Wood, Mc Inish and Ord (1985). The majority of these studies showed that the trading volume, return volatility and liquidity profile follow the U-shaped. All these variables are at the highest level at the opening of trading, they decline rapidly to lower levels lower in the middle and then they increase again during the final minutes of trading. We have tried to verify the existence of seasonality in trading activity, volatility and liquidity, and especially to show the reasons for this anomaly in the Tunisian stock market: a market governed by the orders. To achieve this goal, we have used a sample of high-frequency data for a period which runs from October 2008 until June 2009. We have applied two methods: the temporal analysis is to estimate a dichotomic model for each variable by following the methodological approach of Vo (2007) and the second method is to apply the spectrum analysis by using the Fourier Transform fast (FFT). The results have shown that all identified variables are characterized by a notable seasonality justified the rejection of the hypothesis of constancy (H0). Both methods have shown the existence a seasonal pattern in $\mathrm{U}$. The reason considered to justify this intraday behavior is the crucial role played by the problem of adverse selection especially between the two dimensions of liquidity: the spread and the depth at the best limit. We should also note that the effect of inventory management on the optimal allocation of the portfolio.

\section{References}

Abhyankar, A., Ghosh, D., Levin, E., \& Limmack, R.J. (1997). Bid-Ask spreads, trading volume and volatility: Intraday evidence from the London Stock Exchange. Journal of Business Finance and Accounting, 24(3/4). 343-362. http://dx.doi.org/10.1111/1468-5957.00108

Admati, A.R., \& Pfleiderer, P. (1988). A Theory of Intraday Patterns: Volume and Price Variability. Review of Financial Studies, 1, 3-40. http://dx.doi.org/10.1093/rfs/1.1.3

Admati, A.R., \& Pfleiderer, P. (1989). Divide and conquer: a theory of intraday and day-of-the-week effects. Review of Financial Studies, 2, 189-223. http://dx.doi.org/10.1093/rfs/2.2.189

Ahn, H., \& Cheung, Y-L. (1999). The intraday patterns of the spread and depth in a market without market makers: The Stock Exchange of Hong Kong. Pacific-Basin Finance Journal, 7, 539-556. http://dx.doi.org/10.1016/S0927-538X(99)00023-2

Ahn, H., Bae, K., \& Chan, K. (2001). Limit orders, depth, and volatility: Evidence from the stock exchange of Hong Kong. Journal of Finance, 56, 767-788. http://dx.doi.org/10.1111/0022-1082.00345

Amihud, Y., \& Mendelson, H. (1987). Trading mechanisms and stock returns: an empirical investigation. Journal of finance, 42, 533-553. http://dx.doi.org/10.2307/2328369

Andersen, T. (1996). Return volatility and trading volume: an information flow interpretation of stochastic volatility. Journal of Finance, 51, 169-204. http://dx.doi.org/10.2307/2329306

Barclay, M.J., Litzenberger, R.H., \& Warner, J.B. (1990). Private information, trading volume, and stock-return variances. Review of Financial Studies, 3, 233-253. http://dx.doi.org/10.1093/rfs/3.2.233

Biais, B., Hillion, P., \& Spatt, C. (1995). An empirical analysis of the limit order book and the order flow in the Paris bourse. Journal of Finance, 50, 1655-1689. http://dx.doi.org/10.2307/2329330

Bildik, R. (2001).Intra-day seasonalities on stock returns : evidence from the Turkish stock market. Emerging Market Review, 2, 387-417. http://dx.doi.org/10.1016/S1566-0141(01)00026-7

Brailsford, T. J. (1996) .The empirical relationship between trading volume, returns and volatility. Accounting and Finance, 36, 89-111. http://dx.doi.org/10.1111/j.1467-629X.1996.tb00300.x

Brock, W., \& Kleidon, A. (1992). Periodic market closure and trading volume: A model of intraday bids and asks. Journal of Economic Dynamic and Control, 16, 451-489. http://dx.doi.org/10.1016/0165-1889(92)90045-G

Brockman, P., \& Chung, D.Y. (1998). Inter- and Intra-day Liquidity Patterns on the Stock Exchange of Hong Kong. Journal of International Financial Markets, Institutions and Money, 8, 279-300. http://dx.doi.org/10.1016/S1042-4431(98)00040-7

Brockman, P., \& Chung, D.Y. (1999). An Analysis of Depth Behavior in an Electronic, Order-Driven Environment. Journal of Banking and Finance, 23, 1861-1886. http://dx.doi.org/10.1016/S0378-4266(99)00044-8

Brockman, P., \& Chung, D.Y. (2001). Managerial Timing and Corporate Liquidity: Evidence from Actual Share Repurchases. Journal of Financial Economics, 61, 417-448. http://dx.doi.org/10.1016/S0304-405X(01)00068-X

Chan, K. C., Christie, W. G., \& Schultz, P. H. (1995). Market structure and the intraday pattern of bid-ask spreads for Nasdaq securities. Journal of Business, 68, 35-60. http://dx.doi.org/10.1086/296652 
Chan, K., Chung, Y. P., \& Johnson, H. (1993). Why Option Prices Lag Stock Prices: A Trading Based Explanation. Journal of Finance, 48,1957-1968. http://dx.doi.org/10.2307/2329075

Chen, M., Chow, E. H., Liu, V. W., \& Liu, J. Y. J. (1994). Intraday Stock Returns of Taiwan: An Examination of Transaction Data. National Central University, Working Paper, pp. 1-45.

Cheung, S.C., \& Kwan, C. Y. (1992). A Note on the Transmission of Public Information across International Stock Markets. Journal of Banking and Finance, 16, 831-837. http://dx.doi.org/10.1016/0378-4266(92)90011-N

Choe, H., \& Shin, H. (1993). An Analysis of Interday and Intraday Return Volatility-Evidence from the Korea Stock Exchange. Pacific Basin Finance Journal, 1, 175-188. http://dx.doi.org/10.1016/0927-538X(93)90007-5

Chung, D.Y. (2002). The impact of informed trading on corporate Liquidity Paul Brockman. Journal of Multinational Financial Management, 12, 239-259. http://dx.doi.org/10.1016/S1042-444X(01)00053-6

Chung, K. H., \& Van Ness, R. A. (2001). Order handling rules, tick size, and the intraday pattern of bid-ask spreads for Nasdaq stocks. Journal of Financial Markets, 4, 143-161. http://dx.doi.org/10.1016/S1386-4181(00)00021-5

Clark, P. K. (1973). A subordinated stochastic process model with finite variance for speculative prices. Econometrica, 41, 135-156. http://dx.doi.org/10.2307/1913889

Comerton-Forde C., Lau, S. T., \& McInish, T. (2007). Opening and closing behavior following the introduction of call auctions in Singapore. Pacific Basin Finance Journal 15(1), 18-35. http://dx.doi.org/10.1016/j.pacfin.2006.04.002

Copeland, L., \& Jones, S.A. (2002). Intradaily Patterns in the Korean Index Futures Market. Asian Economic Journal,16,153-74. http://dx.doi.org/10.1111/1467-8381.00146

Degennaro, R., \& Shrieves, R. (1997). Public information releases, private information arrival and volatility in the foreign exchange market. Journal of Empirical Finance, 4, 295-315. http://dx.doi.org/10.1016/S0927-5398(97)00012-1

Easley, D., \& O'Hara, M. (1992). Time and the process of security price adjustment. Journal of Finance, 47, 577-605. http://dx.doi.org/10.2307/2329116

Edmonds, R.J., \& Kutan, A.M. (2002). Is public information really irrelevant in explaining asset returns? Economics Letters, 76, 223-229. http://dx.doi.org/10.1016/S0165-1765(02)00050-2

Foster, F.D., \& Viswanathan, S. (1990). A theory of interday variations in volumes, variances, and trading costs in stock markets. Review of Financial Studies, 3, 593-624. http://dx.doi.org/10.1093/rfs/3.4.593

Foster, F.D., \& Viswanathan, S. (1993). Variations in trading volume, return volatility, and trading costs: evidence on recent price formation models. Journal of Finance, 48, 187-211. http://dx.doi.org/10.2307/2328886

Foucault, T. (1999). Order flow composition and trading costs in a dynamic limit order arket. Journal of Financial Markets, 2, 193-226.http://dx.doi.org/10.1016/S1386-4181(98)00012-3

French, K.R., \& Roll, R. (1986). Stock return variances: The arrival of information and the reaction of traders. Journal of Financial Economics, 17, 5-26. http://dx.doi.org/10.1016/0304-405X(86)90004-8

Gerety, M.S., \& Mulherin, J. H. (1994). Price Formation on Stock Exchanges: The Evolution of Trading Within the Day. Review of Financial Studies, 7, 609-629. http://dx.doi.org/10.1093/rfs/7.3.609

Hamao, Y., \& Hasbrouck, J. (1995). Securities trading in the absence of dealers: Trades and quotes in the Tokyo Stock Exchange. Review of Financial Studies, 8(3), 849-878. http://dx.doi.org/10.1093/rfs/8.3.849

Handa, P. (1992). On the supply of liquidity at the New York and American Stock Exchanges. Working paper. New York University.

Handa, P., Schwartz, R., \& Tiwari, A. (1998). Determinants of the bid-ask spread in an order driven market. Working paper, University of Iowa.

Harris, L. (1986). A transaction data study of weekly and intradaily patterns in stock returns. Journal of Financial Economics, 16, 99-117. http://dx.doi.org/10.1016/0304-405X(86)90044-9

Hasbrouck, J. (1991a). The summary informativeness of stock trades: an econometric analysis. Review of Financial Studies, 4, 571-595. http://dx.doi.org/10.1093/rfs/4.3.571

Hasbrouck, J. (1991b). Measuring the information content of stock trades. Journal of Finance, 46, 179-207. http://dx.doi.org/10.2307/2328693 
Ho, Y.K., \& Cheung, Y.L. (1991). Behavior of Intra-daily Stock Return on an Asian Emerging Market \pm Hong Kong.Applied Economics, 23,957-966. http://dx.doi.org/10.1080/00036849100000044

Ho, Y.K., Cheung, Y.L., \& Cheung, D.W.W. (1993). Intraday Prices and Trading Volume Relationship in an Emerging Asian Market. Pacific Basin Finance Journal, 1, 203-214. http://dx.doi.org/10.1016/0927-538X(93)90009-7

Jain, P., \& Joh, G. (1986). The Dependence between Hourly Prices and Triding Volume. Working Paper, The Wharton School, University of Pennsylvania.

Jain, P., \& Joh, G. (1988). The Dependence Between Hourly Prices and Trading Volume. Journal of Financial and Quantitative Analysis, 23, 269-284. http://dx.doi.org/10.2307/2331067

Jang, H., \& J. Lee. (1993) .Intraday Behavior of the Bid-Ask Spread and Related Trading Variables. Working Paper, University of Oklahoma.

Kalev PS., \& Pham LT (2009). Intraweek and intraday trade patterns and dynamics. Pacific Basin Finance Journal, 17, 547-564. http://dx.doi.org/10.1016/j.pacfin.2009.05.002

Kalev, P.S., Liu, W.M., Pham, P.K., \& Jarnecic, E. (2004). Public information arrival and volatility of intraday stock returns.Journal of Banking and Finance, 28, 1441-1467. http://dx.doi.org/10.1016/S0378-4266(03)00126-2

Kavajecz, K. A. (1999). A Specialist's Quoted Depth and Limit Order Book.Journal of Finance, 54,747-771. http://dx.doi.org/10.1111/0022-1082.00124

Lamoureux, C.G., \& Lastrapes W. D. (1990). Heteroskedasticity in Stock Return Data Volume versus GARCH Effects. Journal of Finance, 45, 221-229. http://dx.doi.org/10.2307/2328817

Lee, C. M., Mucklow, B., \& Ready, M. J. (1993). Spreads, depths and the impact of earnings information: an intraday analysis. Review of Financial Studies, 6(2), 345-374. http://dx.doi.org/10.1093/rfs/6.2.345

Lee, C., \& Ready, M. (1991). Inferring trade direction from intraday data. Journal of Finance, 46, 733-747. http://dx.doi.org/10.2307/2328845

Lee, C.M.C. (1990). Information Dissemination and the Small Trader: An Intraday Analysis of the Small Trader Response to Announcements of Corporate Earnings and Changes in Dividend Policy. Ph.D. dissertation, Cornell University.

Lee, Y-T., Fok R.C.W., \& Liu, Y-J. (2001). Explaining Intraday Pattern of Trading Volume from the Order Flow Data. Journal of Business Finance and Accounting, 28(1) and (2).

Lehmann, B. N., \& Modest, D.M. (1994).Trading and Liquidity on the Tokyo Stock Exchange:A Bird's Rye View. Journal of Finance, 44, 951-984. 329212

Lockwood, L.J., \& Linn, S. C. (1990). An examination of market return volatility during overnight and intraday periods 1964-1989. Journal of Finance, 45, 591-601. http://dx.doi.org/10.2307/2328672

Madhavan, A. (1992). Trading Mechanisms in Stock markets. The Journal of Finance, 47, 607-641 Published by: Blackwell Publishing for the American Finance Association Stable. http://dx.doi.org/10.2307/2329117

Madhavan, R, M., \& Roomans, M. (1997). Why do Security Prices Change? A Transactions Level Analysis of NYSE Stocks, University of Southern California, July, unpublished.

McInish, T.H., \& Wood, R.A. (1985). Intraday and Overnight Returns and Day-Of-The-Week Effect. Journal of Financial Research, 8, 119-26.

McInish, T.H., \& Wood, R.A. (1989). The Dependence of Hourly Volume, Trade Size and Number of Trades on Returns. Working Paper. University of Texas.

McInish, T.H., \& Wood, R.A. (1990a). A Transaction Data Analysis of the Variability of Common Stock Returns During 1980-1984. Journal of Banking and Finance, 14, 113-129. http://dx.doi.org/10.1016/0378-4266(90)90038-4

McInish, T.H., \& Wood, R.A. (1990b). An analysis of transactions data for the Toronto Stock Exchange. Journal of Banking and Finance, 14, 458-491. http://dx.doi.org/10.1016/0378-4266(90)90058-A

McInish, T.H., \& Wood, R.A. (1992). An analysis of intraday patterns in bid/ask spreads for NYSE stocks. Journal of Finance, 47, 753-764. http://dx.doi.org/10.2307/2329122

Naes, R., \& Skjeltorp, J.A. (2006). Order book characteristics and the volume-volatility relation: Empirical evidence from a limit order market. Journal of Financial Markets, 9, 408-432. http://dx.doi.org/10.1016/j.finmar.2006.04.001 
Randi, N., \& Johannes A.S. (2006). Order book characteristics and the volume-volatility relation: Empirical evidence from a limit order market. Journal of Financial Markets, 9, 408-432 http://dx.doi.org/10.1016/j.finmar.2006.04.001

Stoll, H., \& Whaley, R.E. (1990). Stock Market Structure and Volatility. Review of Financial Studies, 3, 37-71. http://dx.doi.org/10.1093/rfs/3.1.37

Tauchen, G., \& Pitts, M. (1983) .The price variability-volume relationship on Speculative markets. Econometrica, 51,485-505. http://dx.doi.org/10.2307/1912002

Vo, M.T. (2007). Limit orders and the intraday behaviour of market liquidity: Evidence from the Toronto stock exchange. Gobal Finance Journal, 17, 379-396. http://dx.doi.org/10.1016/j.gfj.2006.06.012

Wood, R.A., McInish, T.H., \& Ord, J.K. (1985). An Investigation of Transaction Data for NYSE Stocks. Journal of Finance, 40, 723-739. http://dx.doi.org/10.2307/2327796

Ye, J. (1995). Bid-Ask prices and sizes: The specialist's optimal quotation strategy. Working Paper. University of Southern California. 
Table 1. The list of shares listed continuously on the Tunisian stock market during the period October 2008 - June 2009

\begin{tabular}{|c|c|c|}
\hline Code & Stock & INDUSTRY \\
\hline 725001 & ADWYA & Health \\
\hline 340005 & AMEN BANK & Financials \\
\hline 730001 & ARTES & Consumer services \\
\hline 714001 & ASSAD & Consumer goods \\
\hline 360035 & ATB & Financials \\
\hline 470010 & ATL & Financials \\
\hline 160015 & ATTIJARI BANK & Financials \\
\hline 190060 & $\mathrm{BH}$ & Financials \\
\hline 180045 & BIAT & Financials \\
\hline 310060 & BNA & Financials \\
\hline 220005 & $\mathrm{BT}$ & Financials \\
\hline 130055 & BTE-ADP & Financials \\
\hline 420085 & CIL & Financials \\
\hline 720001 & EL WIFACK LEASING & Financials \\
\hline 665001 & ELECTROSTAR & Consumer goods \\
\hline 721001 & ESSOUKNA & Industrials \\
\hline 713001 & GIF & Consumer goods \\
\hline 644001 & MAGASIN GENERAL & Consumer services \\
\hline 100010 & MONOPRIX & Consumer services \\
\hline 570001 & POULINAGROUP HLD & Financials \\
\hline 110025 & SFBT & Consumer goods \\
\hline 659001 & SIAME & Industrials \\
\hline 400005 & SIMPAR & Industrials \\
\hline 667001 & SIPHAT & Health \\
\hline 718001 & SITS & Industrials \\
\hline 678001 & SOMOCER & Industrials \\
\hline 653001 & SOTETEL & Telecommunication \\
\hline 666001 & SOTRAPIL & Oil and Gas \\
\hline 658001 & SOTUMAG & Consumer services \\
\hline 656001 & SOTUVER & Industrials \\
\hline 140070 & SPDIT-SICAF & Financials \\
\hline 606001 & STAR & Financials \\
\hline 260095 & STB & Financials \\
\hline 727001 & TPR & Basic Material \\
\hline 410020 & TUNINVEST-SICAR & Financials \\
\hline 120040 & TUNISAIR & Consumer services \\
\hline 210090 & TUNISIE LEASING & Financials \\
\hline 390010 & UIB & Financials \\
\hline
\end{tabular}


Table 2. Descriptive statistics over the period October 2008 - June 2009

\begin{tabular}{|c|c|}
\hline Variables & Value \\
\hline Number of companies & 38 \\
\hline Trading days & 184 \\
\hline Number of transactions & 240564 \\
\hline Quantities of transactions & 121399567 \\
\hline Daily Average of the number of transactions by stock & 34 \\
\hline Total maximum quantity traded for Attijari Bank & 20163175 \\
\hline Total minimum quantity traded for BTE-ADP & 119409 \\
\hline Average daily of trading volume by the action & 17506 \\
\hline Number of purchase orders submitted & 170413 \\
\hline Quantities of stocks submitted by purchase orders & 130262717 \\
\hline Number of sale orders submitted & 158099 \\
\hline Quantities of stocks submitted by sale orders & 130616034 \\
\hline
\end{tabular}

Table 3. The standardized average of return, trading volume, return volatility, spread and depth of 38 shares quoted in the Tunisian stock market during the period of October 2008-June 2009.

\begin{tabular}{|c|c|c|c|c|c|}
\hline Time Interval & Stand return & Stand trading volume & Stand return volatility & Stand quoted spread & Stand depth \\
\hline 10:00:00-10:10:00 & 0.8994 & 3.8556 & 6.5690 & -0.2669 & 3.2521 \\
\hline 10:10:00-10:20:00 & -0.3397 & 0.1709 & 2.1558 & -1.0366 & 3.0942 \\
\hline 10:20:00-10:30:00 & -0.2573 & 0.2864 & 0.7928 & -1.9360 & 2.5917 \\
\hline 10:30:00-10:40:00 & -0.4611 & 0.2675 & -0.1478 & -1.5782 & 2.1298 \\
\hline 10:40:00-10:50:00 & -0.4635 & 0.5032 & 0.2974 & -1.3097 & 1.9516 \\
\hline 10:50:00-11:00:00 & -0.5281 & 0.6226 & 0.2563 & -1.2487 & 1.5843 \\
\hline 11:00:00-11:10:00 & -0.2454 & 0.4679 & -0.1482 & -0.7586 & 1.1715 \\
\hline 11:10:00-11:20:00 & -0.4800 & 0.6026 & 0.0554 & -0.8748 & 1.0153 \\
\hline 11:20:00-11:30:00 & -0.2340 & 0.8543 & -0.1303 & -0.5915 & 0.8403 \\
\hline 11:30:00-11:40:00 & -0.2640 & 0.3362 & -0.4138 & -0.5413 & 0.1713 \\
\hline 11:40:00-11:50:00 & -0.2174 & 0.5057 & -0.3939 & -0.3601 & 0.2582 \\
\hline 11:50:00-12:00:00 & -0.1775 & 0.1502 & -0.6186 & -0.1237 & -0.0843 \\
\hline $12: 00: 00-12: 10: 00$ & -0.2285 & -0.1036 & -0.7242 & 0.0330 & -0.2031 \\
\hline $12: 10: 00-12: 20: 00$ & 0.1890 & -0.8539 & -0.9079 & -0.0724 & -0.9182 \\
\hline $12: 20: 00-12: 30: 00$ & -0.1872 & -1.0989 & -1.1878 & -0.2090 & -0.9698 \\
\hline $12: 30: 00-12: 40: 00$ & 0.0289 & -0.9780 & -0.7344 & 0.4608 & -1.4721 \\
\hline $12: 40: 00-12: 50: 00$ & -0.0009 & -1.5465 & -1.0798 & 0.6596 & -1.4800 \\
\hline $12: 50: 00-13: 00: 00$ & 0.0824 & -1.5922 & -0.6250 & 0.6435 & -1.7698 \\
\hline 13:00:00-13:10:00 & 0.0269 & -1.4585 & -0.9340 & 0.5848 & -2.0680 \\
\hline $13: 10: 00-13: 20: 00$ & -0.2196 & -1.4928 & -0.8808 & 0.7660 & -2.2019 \\
\hline $13: 20: 00-13: 30: 00$ & 0.4064 & -1.5666 & -0.8513 & 1.3140 & -2.4283 \\
\hline $13: 30: 00-13: 40: 00$ & 0.1778 & -1.1224 & -0.8307 & 1.5469 & -2.1907 \\
\hline $13: 40: 00-13: 50: 00$ & 0.5659 & 0.3719 & -0.3692 & 1.8643 & -1.5452 \\
\hline 13:50:00-14:00:00 & 1.9276 & 2.8180 & 0.8515 & 3.0349 & -0.7290 \\
\hline
\end{tabular}


Table 4. Estimation of different models of the intraday liquidity, volatility of return and trading activity for the 38 stocks quoted in the Tunisian stock market during the period of October 2008-June 2009.

\begin{tabular}{|c|c|c|c|c|c|c|}
\hline & & Stand return & Stand trading volume & Stand return volatility & Stand quoted spread & Stand depth \\
\hline \multirow[t]{2}{*}{$\alpha_{0}$} & Coefficient & $-0,1086$ & $-0,0295$ & $-0,3392$ & $-0,0671$ & $-0,1215$ \\
\hline & $\mathrm{t}$-statistic & $-2,1150^{* *}$ & $-0,6476$ & $-7,4333^{*}$ & $-1,6051$ & $-3,7709^{*}$ \\
\hline \multirow[t]{2}{*}{$\alpha_{1}$} & Coefficient & 1,0080 & 2,0049 & 3,7102 & $-0,0698$ & 1,7903 \\
\hline & $\mathrm{t}$-statistic & $8,7793 *$ & $19,6436^{*}$ & $36,3517^{*}$ & $-0,7468$ & $24,842 *$ \\
\hline \multirow[t]{2}{*}{$\alpha_{2}$} & Coefficient & $-0,2311$ & 0,1554 & 1,4455 & $-0,4648$ & 1,7093 \\
\hline & t-statistic & $-2,0128 * * *$ & 1,5230 & $14,1635^{*}$ & $-4,9693^{*}$ & $23,7180^{*}$ \\
\hline \multirow[t]{2}{*}{$\alpha_{3}$} & Coefficient & $-0,1487$ & 0,2134 & 0,7461 & $-0,9263$ & 1,4515 \\
\hline & t-statistic & $-1,2950$ & $2,0913^{* *}$ & $7,3105^{*}$ & $-9,9031 *$ & $20,1404 *$ \\
\hline \multirow[t]{2}{*}{$\alpha_{4}$} & Coefficient & $-0,3525$ & 0,1725 & 0,2634 & $-0,7427$ & 1,2144 \\
\hline & t-statistic & $-3,0702^{*}$ & $1,6904 * *$ & $2,5810^{* *}$ & $-7,9403 *$ & $16,8511^{*}$ \\
\hline \multirow[t]{2}{*}{$\alpha_{5}$} & Coefficient & $-0,3549$ & 0,2772 & 0,4919 & $-0,6049$ & 1,1230 \\
\hline & t-statistic & $-3,0909^{*}$ & $2,7162^{*}$ & $4,8199 *$ & $-6,4675^{*}$ & $15,5829^{*}$ \\
\hline \multirow[t]{2}{*}{$\alpha_{6}$} & Coefficient & $-0,4195$ & 0,3980 & 0,4708 & $-0,5736$ & 0,9345 \\
\hline & t-statistic & $-3,6540^{*}$ & $3,8995^{*}$ & $4,6130^{*}$ & $-6,1328^{*}$ & $12,9673^{*}$ \\
\hline \multirow[t]{2}{*}{$\alpha_{7}$} & Coefficient & $-0,1368$ & 0,2561 & 0,2632 & $-0,3221$ & 0,7227 \\
\hline & $\mathrm{t}$-statistic & $-1,1916$ & $2,5096^{* *}$ & $2,5788^{* *}$ & $-3,4439^{*}$ & $10,0284^{*}$ \\
\hline \multirow[t]{2}{*}{$\alpha_{8}$} & Coefficient & $-0,3714$ & 0,3108 & 0,3677 & $-0,3817$ & 0,6425 \\
\hline & t-statistic & $-3,2347^{*}$ & $3,0454 *$ & $3,6030^{*}$ & $-4,0814^{*}$ & $8,9162 *$ \\
\hline \multirow[t]{2}{*}{$\alpha_{9}$} & Coefficient & $-0,1254$ & 0,4510 & 0,2724 & $-0,2363$ & 0,5527 \\
\hline & t-statistic & $-1,0924$ & $4,4193^{*}$ & $2,6689 * *$ & $-2,5271^{*}$ & $7,6702 *$ \\
\hline \multirow[t]{2}{*}{$\alpha_{10}$} & Coefficient & $-0,1554$ & 0,1710 & 0,1269 & $-0,2106$ & 0,2094 \\
\hline & t-statistic & $-1,3539$ & 1,6761 & 1,2435 & $-2,2517 * *$ & $2,9066^{*}$ \\
\hline \multirow[t]{2}{*}{$\alpha_{15}$} & Coefficient & $-0,0786$ & $-0,4973$ & $-0,2702$ & $-0,0401$ & $-0,3761$ \\
\hline & t-statistic & $-0,6847$ & $-4,8730^{*}$ & $-2,6480 * *$ & $-0,4289$ & $-5,2195^{*}$ \\
\hline \multirow[t]{2}{*}{$\alpha_{16}$} & Coefficient & 0,1375 & $-0,4699$ & $-0,0375$ & 0,3036 & $-0,6339$ \\
\hline & t-statistic & 1,1980 & $-4,6047^{*}$ & $-0,3682$ & $3,2460^{*}$ & $-8,7958^{*}$ \\
\hline \multirow[t]{2}{*}{$\alpha_{17}$} & Coefficient & 0,1076 & $-0,7898$ & $-0,2148$ & 0,4056 & $-0,6379$ \\
\hline & $\mathrm{t}$-statistic & 0,9378 & $-7,7384^{*}$ & $-2,1048$ & $4,3365^{*}$ & $-8,8519^{*}$ \\
\hline \multirow[t]{2}{*}{$\alpha_{18}$} & Coefficient & 0,1911 & $-0,8213$ & 0,0185 & 0,3974 & $-0,7866$ \\
\hline & t-statistic & 1,6644 & $-8,0471^{*}$ & 0,1816 & $4,2485^{*}$ & $-10,915^{*}$ \\
\hline \multirow[t]{2}{*}{$\alpha_{19}$} & Coefficient & 0,1355 & $-0,7325$ & $-0,1400$ & 0,3672 & $-0,9396$ \\
\hline & $\mathrm{t}$-statistic & 1,1805 & $-7,1770^{*}$ & $-1,3719$ & $3,9265^{*}$ & $-13,038^{*}$ \\
\hline \multirow[t]{2}{*}{$\alpha_{20}$} & Coefficient & $-0,1110$ & $-0,7356$ & $-0,1127$ & 0,4602 & $-1,0084$ \\
\hline & t-statistic & $-0,9673$ & $-7,2073^{*}$ & $-1,1042$ & $4,9205^{*}$ & $-13,992 *$ \\
\hline \multirow[t]{2}{*}{$\alpha_{21}$} & Coefficient & 0,5150 & $-0,7997$ & $-0,0975$ & 0,7414 & $-1,1245$ \\
\hline & $\mathrm{t}$-statistic & $4,4860^{*}$ & $-7,8358^{*}$ & $-0,9559$ & $7,9265^{*}$ & $-15,604^{*}$ \\
\hline \multirow[t]{2}{*}{$\alpha_{22}$} & Coefficient & 0,2864 & $-0,5607$ & $-0,0870$ & 0,8609 & $-1,0026$ \\
\hline & t-statistic & $2,4945^{*}$ & $-5,4945^{*}$ & $-0,8525$ & $9,2041^{*}$ & $-13,911^{*}$ \\
\hline \multirow[t]{2}{*}{$\alpha_{23}$} & Coefficient & 0,6745 & 0,2119 & 0,1497 & 1,0238 & $-0,6714$ \\
\hline & t-statistic & $5,8746^{*}$ & $2,0762 * *$ & 1,4675 & $10,9456^{*}$ & $-9,3160 *$ \\
\hline \multirow[t]{2}{*}{$\alpha_{24}$} & Coefficient & 2,0362 & 1,4940 & 0,7762 & 1,6245 & $-0,2526$ \\
\hline & t-statistic & $17,733^{*}$ & $14,6381 *$ & $7,6056^{*}$ & $17,3673^{*}$ & $-3,5049^{*}$ \\
\hline
\end{tabular}

Notes: *** 10\% significance level, $* * 5 \%$ significance level, $* 1 \%$ significance level 
Table 5. Matrix of unconditional correlation between all variables

\begin{tabular}{|c|c|c|c|c|c|c|}
\hline & Variables & $\begin{array}{l}\text { Stand } \\
\text { return }\end{array}$ & Stand trading volume & $\begin{array}{c}\text { Stand return } \\
\text { volatility }\end{array}$ & $\begin{array}{c}\text { Stand quoted } \\
\text { spread } \\
\end{array}$ & Stand depth \\
\hline \multirow{5}{*}{ All intervals } & Stand return & 1.0000 & 0.4129 & 0.3247 & 0.7775 & -0.2703 \\
\hline & Stand trading volume & & 1.0000 & 0.7821 & -0.1145 & 0.6688 \\
\hline & Stand return volatility & & & 1.0000 & -0.1937 & 0.6760 \\
\hline & Stand quoted spread & & & & 1.0000 & -0.7604 \\
\hline & Stand depth & & & & & 1.0000 \\
\hline \multirow{5}{*}{$\begin{array}{l}\text { The first three } \\
\text { intervals }\end{array}$} & Stand return & 1.0000 & 0.9994 & 0.9590 & 0.8092 & 0.6404 \\
\hline & Stand trading volume & & 1.0000 & 0.9675 & 0.8275 & 0.6646 \\
\hline & Stand return volatility & & & 1.0000 & 0.9425 & 0.8317 \\
\hline & Stand quoted spread & & & & 1.0000 & 0.9694 \\
\hline & Stand depth & & & & & 1.0000 \\
\hline \multirow{5}{*}{$\begin{array}{l}\text { The eighteen } \\
\text { intervals within the } \\
\text { trading day }\end{array}$} & Stand return & 1.0000 & -0.7616 & -0.7346 & 0.8534 & -0.8314 \\
\hline & Stand trading volume & & 1.0000 & 0.8342 & -0.8609 & 0.9166 \\
\hline & Stand return volatility & & & 1.0000 & -0.8088 & 0.8685 \\
\hline & Stand quoted spread & & & & 1.0000 & -0.9716 \\
\hline & Stand depth & & & & & 1.0000 \\
\hline \multirow{5}{*}{$\begin{array}{l}\text { The last three } \\
\text { intervals }\end{array}$} & Stand return & 1.0000 & 0.9851 & 0.9984 & 0.9999 & 0.9704 \\
\hline & Stand trading volume & & 1.0000 & 0.9932 & 0.9836 & 0.9974 \\
\hline & Stand return volatility & & & 1.0000 & 0.9979 & 0.9824 \\
\hline & Stand quoted spread & & & & 1.0000 & 0.9683 \\
\hline & Stand depth & & & & & 1.0000 \\
\hline
\end{tabular}

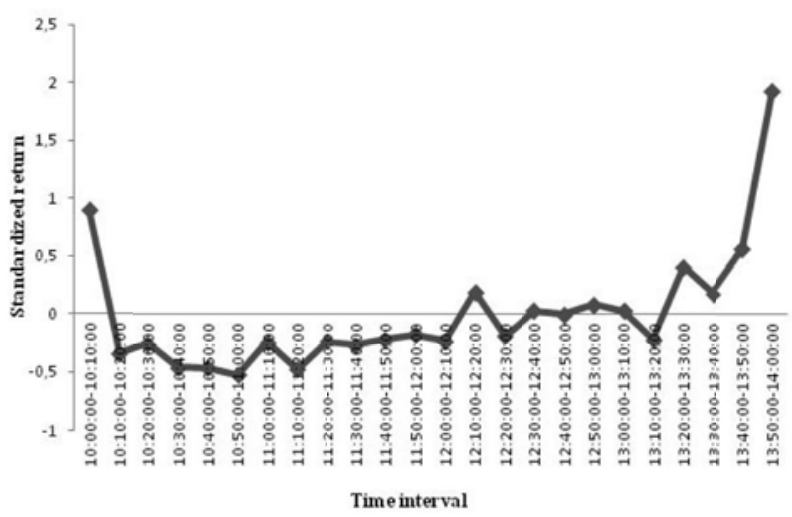

Figure 1. Evolution of intraday standardized return

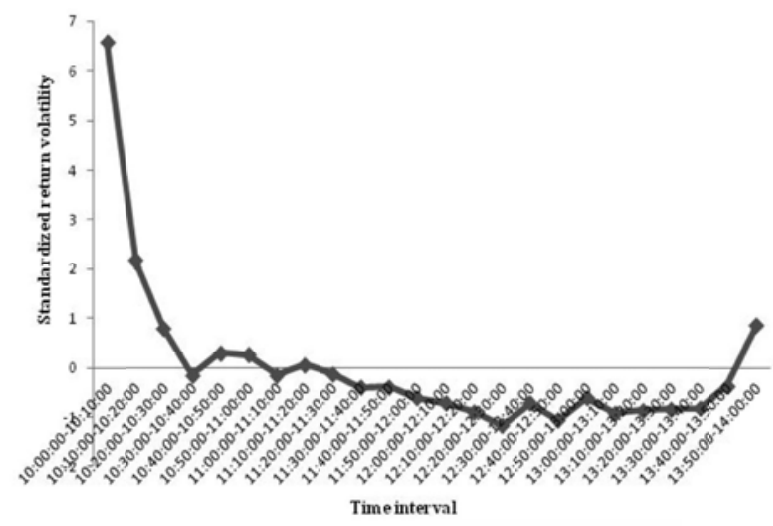

Figure 3. Evolution of intraday standardized return volatility

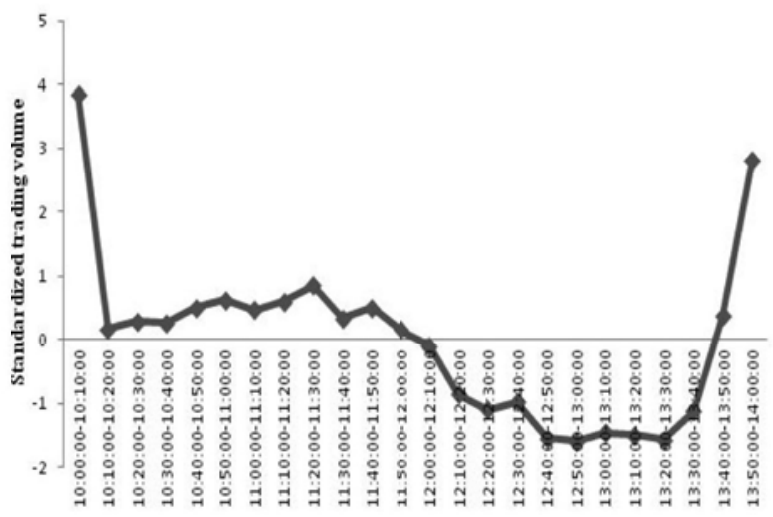

Figure 2. Evolution of intraday standardized trading volume

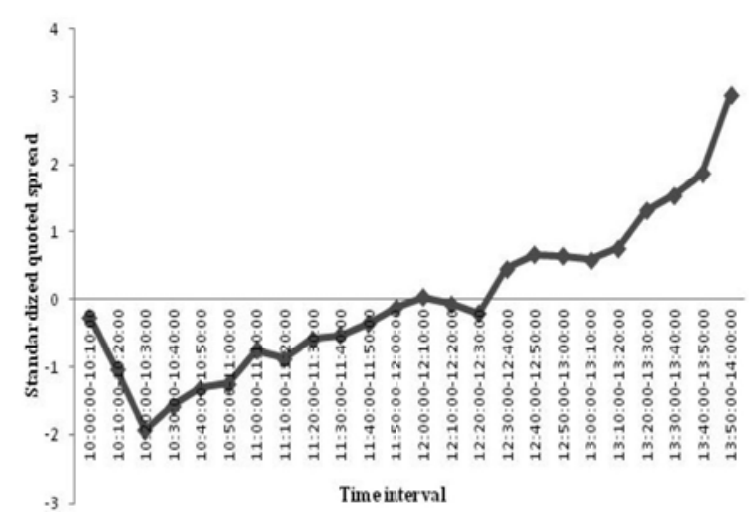

Figure 4. Evolution of intraday standardized quoted spread 


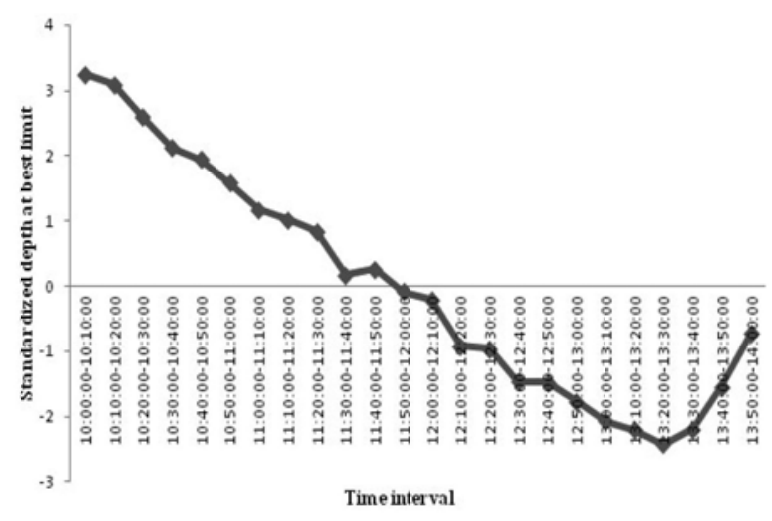

Fugure 5. Evolution of intraday standardized depth at best limit

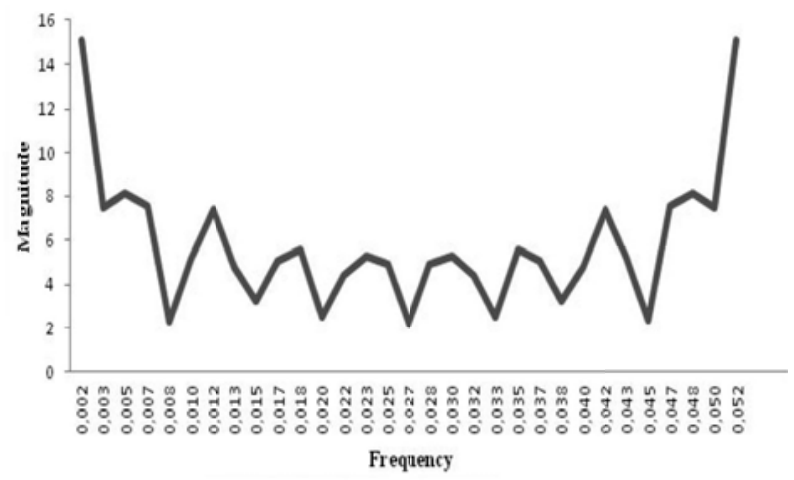

Figure 7. The trading volume spectrum obtained by FFT

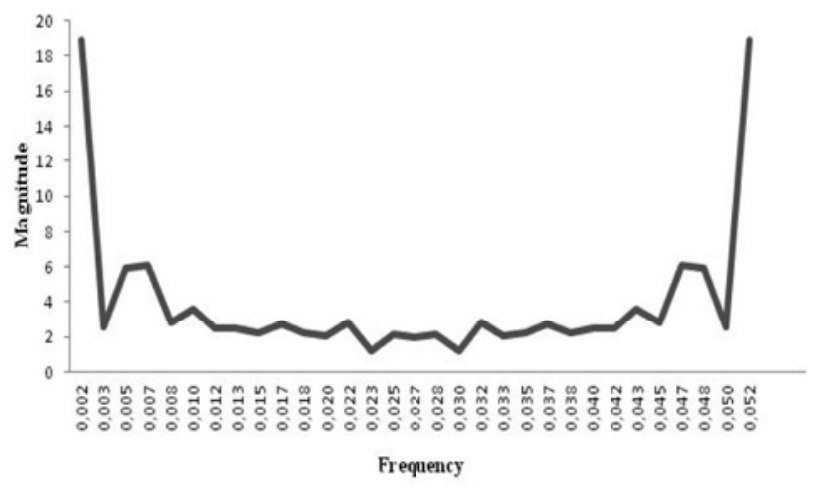

Figure 9. The quoted spread spectrum obtained by FFT

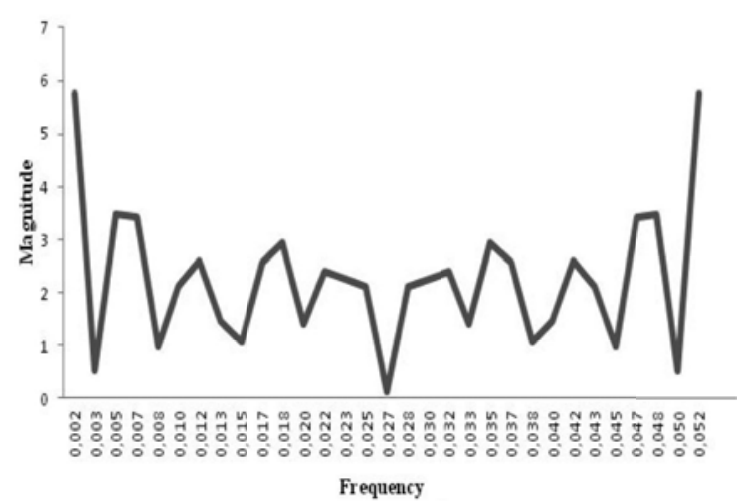

Figure 6. The return spectrum obtained by FFT

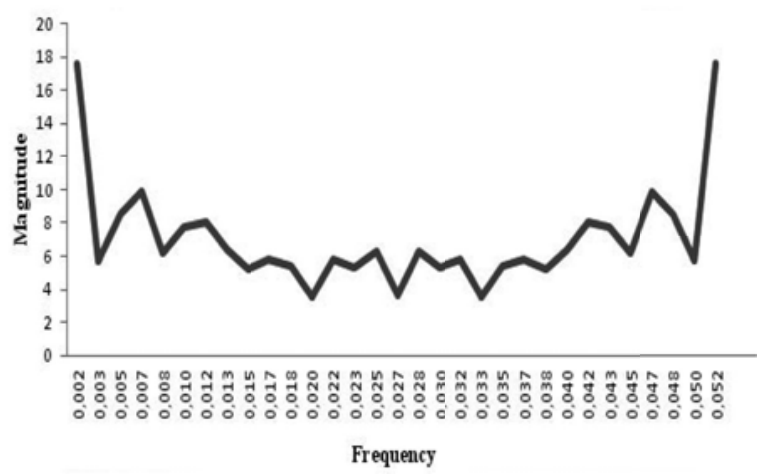

Figure 8 . The return volatility spectrum obtained by FFT

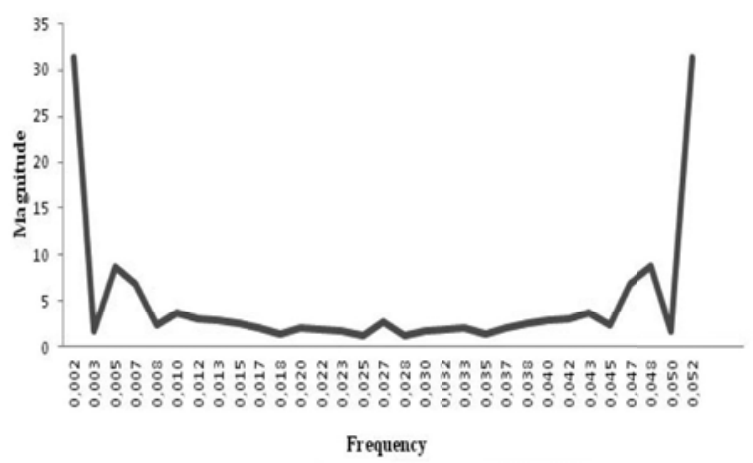

Figure 10. The depth spectrum obtained by FFT 